\title{
Evaluation of Equipment Maintenance Support Processes Based on ANP
}

\author{
Xiang Zhao ${ }^{1}$, Gang Chen ${ }^{2}$ and Ning Zhu $^{3}$ \\ ${ }^{1}$ Dept. of Equipment Command and Management, Shijiazhuang Mechanical Engineering College, Shijiazhuang 050003, China \\ ${ }^{2}$ College of information technology \& cultural management, Hebei Institute of Communication, Shijiazhuang 050000, China
}

\begin{abstract}
Under the new military change, it needs to evaluate the equipment maintenance support processes before optimizing it. For this reason, this paper proposes an evaluation method of equipment maintenance support processes based on ANP through establishing the evaluation index system and adopting ANP method to deal with the indexes that associated with each other. Finally, the paper applied it to a case of subject research to verify its validity and practicability.
\end{abstract}

Keywords-equipment maintenance support; operation process; index system; interrelation; analytic network process (ANP)

\section{INTRODUCTION}

Developments of the information technology have an impact on the equipment maintenance support working model and operation. The operation process optimizing problem has been taken on the agenda. On the one hand, the utilization of the information technology shortens the distance of time and space; fasten the speed and precision of the info-transmitting. It also broadens the operation processes covering fields and increases the information exchange amount. On the other hand, the new military change which is brought by the information technology makes the equipment maintenance support task change a lot. It's of great necessary for the traditional operation process to make adaptation according to the changes. The optimizing of the equipment maintenance support operation processes is also beneficial for the equipment maintenance support informatization.

In order to realize the optimization of the equipment maintenance support operation processes, we need to make an integrated evaluation of the existed operation processes. According to the evaluation result, the optimization designs will guide the optimizing process implement more accurately. The evaluation process includes three steps: establishing the evaluating index system, choosing evaluation method, evaluating the operation processes.

\section{EVALUATING INDEX SYSTEM OF THE EQUIPMENT MAINTENANCE SUPPORT OPERATION PROCESSES}

\section{A. Establishing the Evaluating Index System}

The purpose of building the index system is to make scientific analysis of the operation process. Evaluation of the equipment maintenance support operation processes is established mainly to solve the following problems:
- If the process can finish the support task on time? If the procedure has the ability of handling an abnormal situation?

- How to minimize the cost with the guarantee of finishing the task?

- If the maintenance support can meet the unit's requirement? In which degree can it meet?

- How long will the whole support process last? How many steps will it need at least? How many steps will it finish within per unit time?

- What is the resources availability of the human, devices and instruments?

- How is the information flow rate and time- efficiency of the operation process?

- How is the quality of the support process?

Aiming at solving the above problems, the paper built the maintenance support operation procedure index system from the 7 aspects. Those are procedure flexible, cost, unit satisfaction degree, procedure efficiency, resources availability, info transmit ability and support quality, which are shown in Fig I.

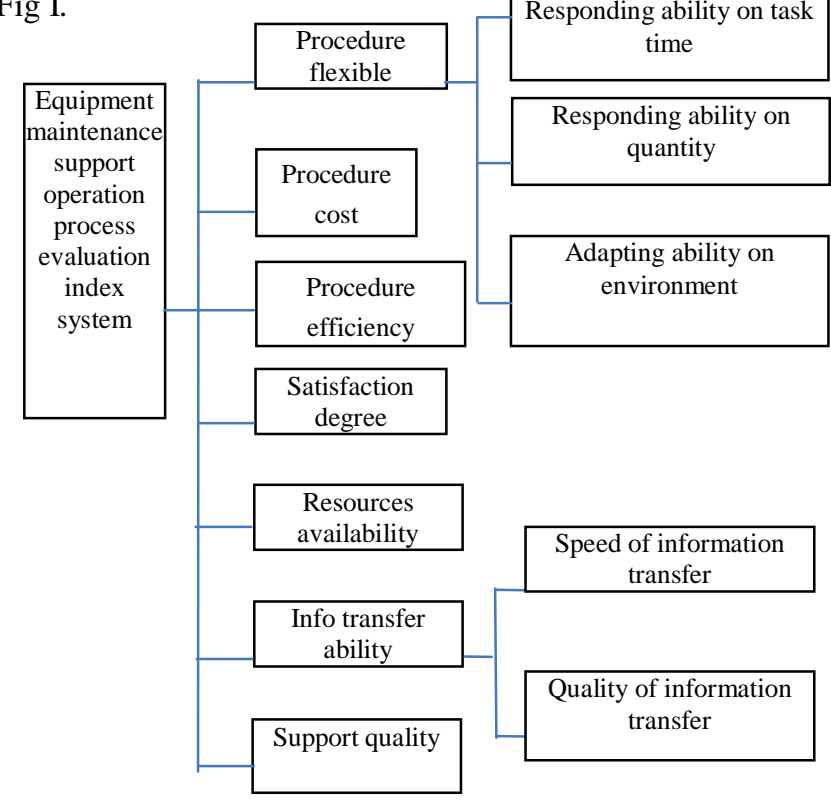

FIGURE I. EQUIPMENT MAINTENANCE SUPPORT OPERATION PROCESS EVALUATION INDEX SYSTEM 


\section{B. Definition of the Evaluation Indexes}

1) Procedure Flexibility Index: The procedure flexibility index is the adaptation ability of the equipment maintenance support operation varies from changes of the unit's requirements and environment. It includes the responding ability on the task time, quality and adaptation ability of environment.

a) $S R_{T}$ : Supposing $\mathrm{t}$ is the resonding time to the task time change, so the responding ability on the task time change during the evaluating time $\mathrm{T}$ is defined as

$$
S R_{T}=\frac{1}{n} \sum_{i=1}^{n} t_{i}
$$

b) $W Q_{T}$ : Supposing Qmax is the maximum value that the maintenance process can support. $\mathrm{D}$ is the unit requirement value. So the responding ability on the quantity is defined as

$$
W Q_{T}=P\left[D \in\left(0, Q_{\max }\right)\right]
$$

c) $H X_{T}$ : Supposing the Ta is the succeed support number of times under the environment change. Tb is the total support number of times. So the adaption ability on the environment change is defined as

$$
H X_{T}=\frac{T_{a}}{T_{b}}
$$

2) Procedure Cost Index: The procedure cost index means the sum of all the cost in the equipment maintenance support information flow and materials flow. $\mathrm{C} 1$ means the acquisition cost, $\mathrm{C} 2$ means the reserve cost, C3means the supply cost. The sum cost $\mathrm{C}$ is defined as

$$
C=C_{1}+C_{2}+C_{3}
$$

3) Unit Satisfaction Degree Index: We can obtain the unit satisfaction degree through the questionnaires. D1 means the sum of all units being investigated. D2 means the satisfied unit numbers. So the unit satisfaction degree is defined as D

$$
D=\frac{D_{2}}{D_{1}}
$$

4) Procedure Efficiency Index: Mean repair time and mean support time can reflect the efficiency of the operation process. They are the most important indexes in the index system.

a) the Mean Repair Time is MT:Supposing the repair times of $\mathrm{N}$ maintenance support are $\mathrm{T}_{1}, \mathrm{~T}_{2}, \mathrm{~T}_{3}, \ldots, \mathrm{T}_{\mathrm{n}}$.

$$
M T=\frac{1}{N} \sum_{i=1}^{N} T_{i}
$$

b) Mean Handle Ability: means the ability of handling tasks during the maintenance process. It is defined as $\mathrm{N}_{\mathrm{d}}$ which is the procedure numbers being handled in the regular time.

5) Resources Availability Index: Resources availability means the availability of human, devices and all kinds of assessments in the whole maintenance support process. Decision maker can sense if the resources are being used rationally through the analysis of the resources availability. By which he can optimize the process. Supposing the Ts is the using time of the resources. Tx is the idle time of the resources. So the Resources availability is defined as RA:

$$
R A=\frac{T_{S}}{T_{X}+T_{S}} \times 100 \%
$$

\section{6) Indexes of Information Transfer ability}

a) The Velocity of Information Transfer: The information transition index can reflect the information transfer ability. It includes the information transmit velocity and accuracy. The quick response and response capability to changes relies on the information transmit velocity. Supposing the transmit time is $t$, so the velocity of information transfer is

$$
v=\frac{1}{t}
$$

b) The Error Ratio : The quality of the information transmitting can be indicated as error ratio. The lower the error ratio is, the higher the transmitting quality is. Supposing the $M$ is the amount bit of the information transmitting. Mi is the effectively information bit being transmitting. So is defined as

$$
\eta=1-\frac{M_{i}}{M}
$$

7) Procedure Quality Index: The procedure quality index is the index describes the quality of the equipment maintenance support. It can be measured by comparing with the equipment quality standard. The wrong operation ratio, unqualified ratio, rework ratio are usually used to be the quality indexes.

\section{Relationship among the Evaluating Indexes of Equipment Maintenance Support Operation Process}

The relationships among the evaluating indexes are shown as Figure V. The indexes are correlated and influenced each other. For instance, in order to enhance the unit's satisfaction, we need to further improve the procedure flexibility, procedure efficiency and information transfer. If the procedure efficiency increased, it will helpful in that decreasing the cost and also raising the resources availability. 


\section{ANP METHOD}

There are many procedure evaluation methods, such as the fuzzy comprehensive evaluation method, correlated matrix method, analysis hierarchy process, etc. These methods can only conduct the evaluating on the index individually without concerning the relationships among the indexes. This paper proposed a new evaluation method of the equipment maintenance support operation process. It can help solve the interaction evaluating problem we are right confronting.

The analytic network process (ANP) by famous Prof.Saaty is an essential decision method for expressing our understanding of complex decision issues. The ANP provides a general framework to deal with decisions without making assumptions about the independence of higher-level elements from lower lever elements and about the independence of the elements within a level as in a hierarchy, so it is a better decision tool, compared with the analytic hierarchy process (AHP). In order to overcame limitations, professor T.L.Saaty provided the feedback AHP method (which is the predecessor of ANP) in $1990^{[5]}$. Based on the ISAHP-IV, he systematically proposed a decision theory which can describe the interaction among the indexes. That is ANP theory, the Analysis Network Process.

\section{The Evaluation Of The Equipment Maintenance SUPPORT OPERATION PROCESS BASED ON ANP}

This method evaluates the quality of the equipment maintenance support operation process through building the index system. Firstly, each index is been evaluated and assigned. Secondly, the integrated evaluation is conducted after the indexes aggregation. The quantization of the index may adopt the expert marking method. Because of the complex correlations among the indexes, the weighted sum method isn't suitable to the aggregation. The decision procedure of ANP was shown in Fig IV.

\section{A. ANP Structure of the Equipment Maintenance Support Operation Process Evaluation Index System}

From the Figure V, the ANP structure is divided into two layers:

1) Control Layer: integrated support ability target layer of equipment maintenance support operation process;

2) Network Layer: 7 evaluated indexes relation layer in equipment maintenance support operation process.

\section{B. Index Importance Evaluation}

\section{1) Computing the Consistence Value:}

Supposing $\mathrm{R}$ is the control layer element, $\mathrm{Ci}$ is the network layer element. So the judgment matrix is divided into two kinds of matrix. One is the individual criterion judgment matrix $A_{R}$ of the control layer element; the other is the criterion judgment matrix $\mathrm{A}_{\mathrm{Ci}}$ of the network layer element. According the $1-9$ criterions, $R$ is the standard; $A_{R}$ is obtained by comparing the relative importance of the network layer elements. Then the maximum property $\lambda_{\max }$ and its property vector $\omega_{\mathrm{R}}$ are being computed out. Then the consistence value comes out.

If the C.I is no larger than 0.1 , the judgment matrix can be accepted. Otherwise is denied. If the property vector $\omega_{R}$ is satisfied the property condition, it should apply the method of normalization. $\omega_{\mathrm{Ci}}$ is computed in the same way as the $\mathrm{A}_{\mathrm{Ci}}$.

2) The Super Matrix $W$ : is conducted by the $\omega_{R}, \omega_{C}$ assemble, which is marked as.

$$
\mathrm{W}=\left(\omega_{c 1}, \omega_{c 2}, \omega_{c 3}, \omega_{c 4}, \omega_{c 5}, \omega_{c 6}, \omega_{c 7}, \omega_{k}\right)
$$

\section{3) Evaluating Value Ai:}

In document 8 , the matrix analysis method is used to be classified by reducibility and its maximum property root. That paper got 6 kinds of super matrixes and adopted 4 computing methods. Because the computing process of the super matrix is complicated, assistant computing are always being used. In this paper, the ANP decision software Super Decision is used for computing. Evaluating value $a_{i}$ which embodies the importance of each index is gotten.

\section{Index Aggregation}

Through the export marking, the weight of index ei is obtained. Combined with the index importance degree evaluating value ai, the final integrated support ability evaluation result came out.

$$
\mathrm{E}_{R}=\sum_{i=1}^{7} e_{i} \bullet a_{i}
$$

\section{CASE ANALYSES}

The research group did an investigation and survey on an equipment maintenance support operation process by carrying out interviews, investigations and also distributing questionnaires, gaining the information of the operation procedure, information process and personnel opinions of operators.

\section{A. Index Assignment}

The research group analyzed the collective data and organized 10 experts marking about 3 operation process: the maintenance plan design, material management and repair quality assessment. Due to the limitation of paper, only the material management values are listed. The value in the table I described the subordination degree to the "excellent, good, bad".

\section{B. Index Aggregation}

We built the ANP structure of the material management ability used Super Decision software and computed the importance degree of the index. It is shown in Figure II. According to the equitation 11, the aggregation is done among the material management indexes. The evaluation result is obtained. 


\section{$\mathrm{E}_{\mathrm{R}}=0.107 \times(0.1,0.4,0.6)+0.033 \times(0,0.5,0.5)+0.083 \times(0.1,0.5,0.4)+0.344 \times(0,0.3,0.7)$ $+0.118 \times(0.1,0.3,0.6)+0.196 \times(0,0.2,0.8)+0.15 \times(0,0.6,0.4)$}

\section{Result Analysis}

The evaluation of the material management is shown in Figure III. From the Figure III, the conclusion is obtained. The membership degree of the excellent is the lowest, the membership degree of the good is medium, and the membership degree of the bad is the highest.

As the result, the evaluating conclusion of the equipment maintenance support operation process is bad. Comparing the importance values in Figure III, the result is mainly affected by the procedure efficient, resource availability and information transmitting ability. The three index evaluating values are bad leading to the integrated evaluation result is bad. Used the same method, the other two operation process, the maintenance plan design and repair quality evaluation were computed using the same method.

\section{TABLE I. INDEX EVALUATING VALUE}

\begin{tabular}{|c|c|c|c|}
\hline index & excellent & good & bad \\
\hline Procedure flexibility & 0.1 & 0.4 & 0.6 \\
\hline Procedure cost & 0.0 & 0.5 & 0.5 \\
\hline Unit satisfaction degree & 0.1 & 0.5 & 0.4 \\
\hline Procedure efficiency & 0.0 & 0.3 & 0.7 \\
\hline Resource availability & 0.1 & 0.3 & 0.6 \\
\hline Information transfer ability & 0.0 & 0.2 & 0.8 \\
\hline Procedure quality & 0.0 & 0.6 & 0.4 \\
\hline
\end{tabular}

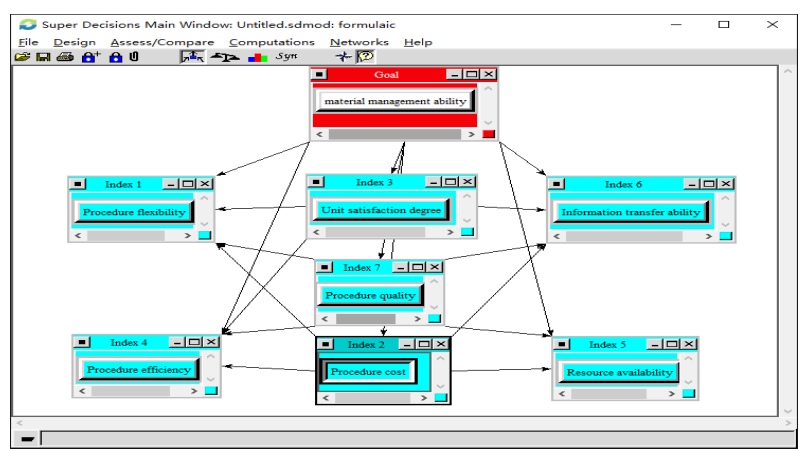

FIGURE II. ANP STRUCTURE OF INDEX SYSTEM IN THE SUPER DECISIONS

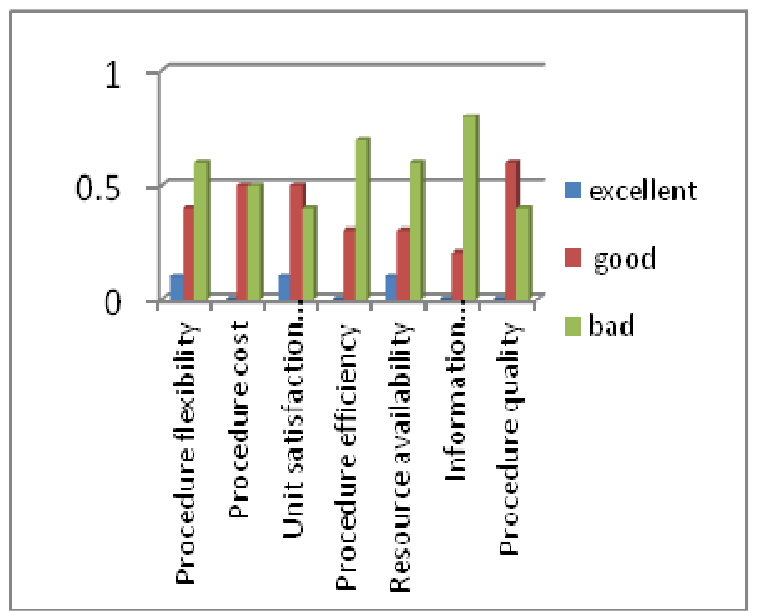

FIGURE III. THE EVALUATION RESULT OF THE MATERIAL MANAGEMENT PROCESS

\section{CONCLUSIONS}

The paper discussed the evaluation method about the equipment maintenance support operation process. It built the evaluation index system and got values through the expert marking. Finally, the index aggregation based on ANP method and got the evaluating result. A case study indicated this method can be adopted to carry out an integrated evaluation of the equipment support operation process.

\section{REFERENCES}

[1] Liu biao, Cai shuqin, Zheng shuangyi. Operation process evaluation index system study[J]. Journal of Huazhong University of Science and Technology.2005 (4): 112-114.

[2] Sun yonghe. Methodology Study on the ANP Based on the Perspective of Nonlinear Complex Systems[D]. Changchun: Jilin University (doctor's degree thesis) 2009

[3] Liu feng. Armored Equipment Traffic management Functional optimization research [D].Beijing: Armored Engineering College (Master's degree thesis).2010

[4] Sun hongcai,Xu guanrao, Tian ping. Design Alternatives Evaluation of Emergency Bridge by Applying Analytic Network Process (ANP)[J] .System Engineering Theory and Practice. 2007(3):63-70.

[5] Saaty T L. Multictiteria Decision Making[M].Pittsburgh: RWS Publications, 1990.

[6] Saaty T L. Decision Making with Dependence and Feedback [M].Pittsburgh: RWS Publications, 1996.

[7] Saaty T L. Decision Making-the Analytic Hierarchy or Network Process ( AHP/ANP ) [J].Journal of System Science and System Engineering,2004(3):7-8

[8] Wu zhibin, Chen yihua. Research on sorting algorithm on ANP super matrix $[\mathrm{C}] / /$ Proceedings of the annual conference on control and decision making in China. Shenyang: Northeastern University Press. 2006:1235 

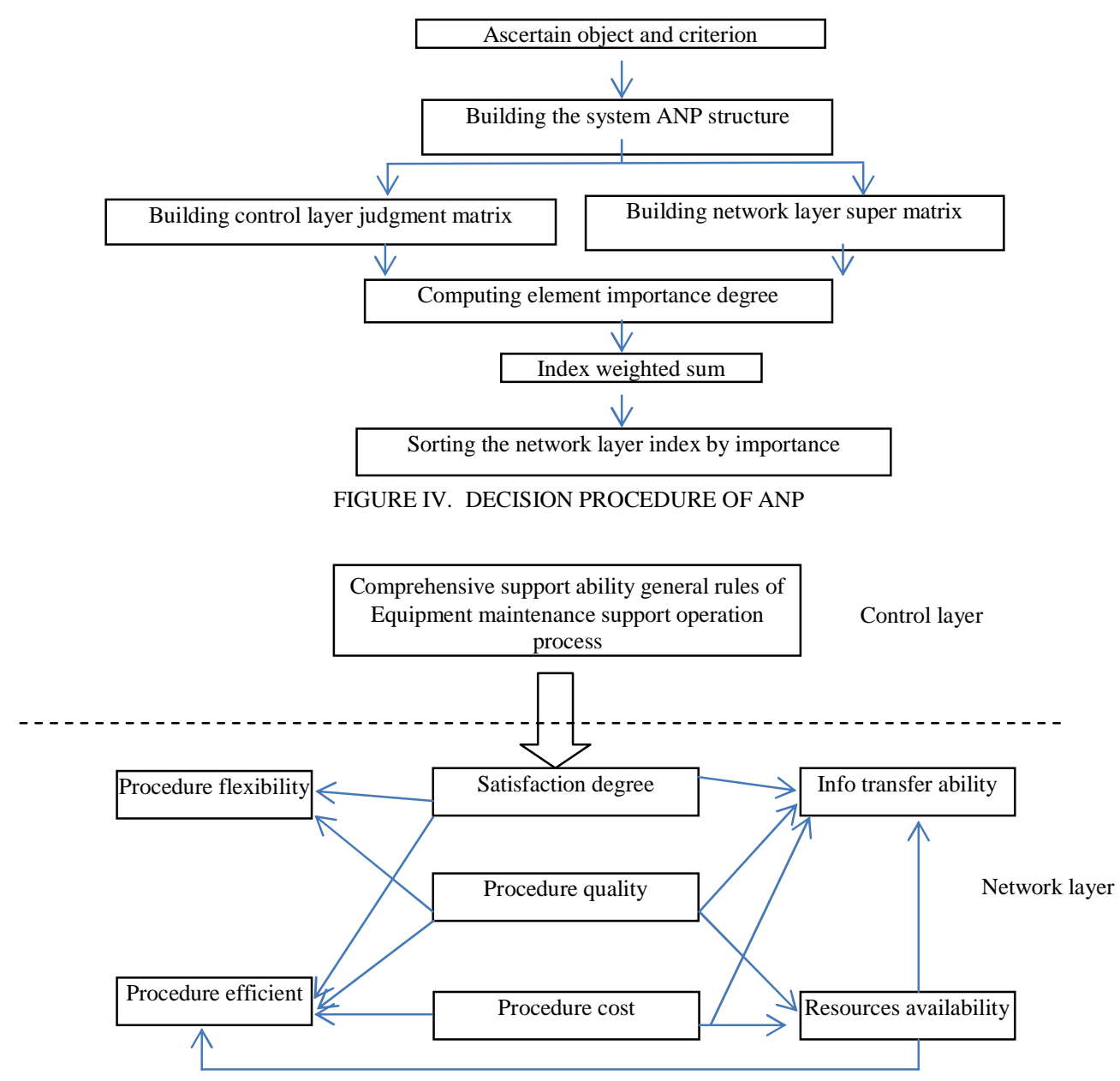

FIGURE V. OPERATION PROCESS EVALUATION INDEX SYSTEM 